Article

\title{
Putting Tasks to the Test: The Case of Germany
}

\author{
Daniela Rohrbach-Schmidt \\ FDZ-Research Data Center, BIBB-Federal Institute for Vocational Education and Training, 53175 Bonn, Germany; \\ E-Mail: rohrbach@bibb.de
}

Submitted: 22 February 2019 | Accepted: 3 June 2019 | Published: 5 September 2019

\begin{abstract}
The demand for skills has changed throughout recent decades, favouring high-skilled workers that perform abstract, problem-solving tasks. At the same time, research shows that occupation-specific skills are beneficial for labour market success. This article explores (1) how education, workplace characteristics and occupations shape job task requirements, (2) how within-occupation job task content relates to wages, and (3) whether these relationships vary across types of tasks due to their presumably varying degrees of occupational specificity. Using worker-level data from Germany from 2011-2012 the article shows that a large part of task content is determined by occupations, but that task requirements also differ systematically within occupations with workers' educational levels and workplace characteristics. Moreover, differences in task usage within occupations are robust predictors of wage differences between workers. Finally, the results suggest that non-routine manual tasks have a higher occupational specificity than abstract and routine tasks, and that manually skilled workers can generate positive returns on their skills in their specific fields of activity.
\end{abstract}

\section{Keywords}

education; job tasks; occupational specificity; wages; worker-level

\section{Issue}

This article is part of the issue "Types of Education, Achievement and Labour Market Integration over the Life Course", edited by Irene Kriesi (Swiss Federal Institute for Vocational Education and Training, Switzerland) and Juerg Schweri (Swiss Federal Institute for Vocational Education and Training, Switzerland).

(C) 2019 by the author; licensee Cogitatio (Lisbon, Portugal). This article is licensed under a Creative Commons Attribution 4.0 International License (CC BY).

\section{Introduction}

The demand for knowledge and skills has changed significantly in Western societies, partly due to technological change. An important research question is therefore which type of skills will be in demand in the future and which educational qualifications are particularly suitable for this. Two strands of literature addressing this question, i.e., the task-approach literature and the literature on occupational specificity are in the foreground in this article.

In the task approach (Autor, Levy, \& Murnane, 2003) aggregate demand for skills is linked with the specific skill demands of jobs. This approach draws an explicit distinction between skills, as characteristics of workers, and tasks, as characteristics of job requirements. The key insight of this conceptualisation is that advances in computer technology throughout recent decades have complemented workers in abstract tasks, substituted for workers in routine tasks, and left most non-routine manual tasks unaffected. Studies in numerous countries have demonstrated a subsequent employment polarization along the occupational distribution (e.g., Autor \& Dorn, 2013; Goos, Manning, \& Salomons, 2014; for Germany see Antonczyk, DeLeire, \& Fitzenberger, 2018; Spitz-Oener, 2006).

Studies referring to the international comparative literature on differences between educational systems (Allmendinger, 1989; Shavit \& Müller, 1998) or the skillweights approach (Lazear, 2009) have focused on the question of whether the specificity of skills is associated with labour market advantages. Vocational education, which on average provides more specific skills than academic education, or programs with a high vocational specificity in general are beneficial for labour market success (e.g., de Lange, Gesthuizen, \& Wolbers, 
2014; Eggenberger, Rinawi, \& Backes-Gellner, 2018; Forster \& Bol, 2018), although some studies show disadvantages of too specific skills later in one's career (Forster \& Bol, 2018; Hanushek, Schwerdt, Woessmann, \& Zhang, 2017).

The aim of this article is to put tasks to a test in Germany, and thereby to deepen the occupation-level argumentation in the task-approach literature by linking this approach to the concept of occupational specificity. This article explores (1) how education, workplace characteristics and occupations shape job task requirements, (2) how within-occupation job task content relates to wages, and (3) whether these relationships vary across types of tasks due to their presumably varying degrees of occupational specificity. The German labour market is especially well suited for this as Germany is a country that stresses vocation-specific training and many jobs have occupational credentialing requirements. In addition, Germany is one of the few exceptions for which person-level task data are available.

From a task-approach perspective, an occupation is conceptualised as an indivisible bundle of task demands that are performed simultaneously by each worker in the occupation to produce output (Autor \& Handel, 2013, p. 64). This implies that occupations should be an important measurable predictor of job tasks. Alternatively, with regard to their job content, occupations should have a small within-variance and high between-occupation variance. In practice, these assumptions are not tested; almost all analyses treat job tasks as an occupationlevel construct (Autor \& Handel, 2013, p. 79). However, Autor and Handel (2013) use a sample of 1,333 workers from the 2008 Princeton Data Improvement Initiative survey (PDII) and 6-digit level occupation information to show that abstract, routine and (non-routine) manual tasks also vary within occupations, are significantly related to workers' characteristics and are robustly predictive of wages. A similar study by Cassidy (2017) studied the task variance within (3-digit) occupations using a sample of around 37,000 West German workers from the 1985-1986 and 1991-1992 German Qualification and Career Survey. Unlike Autor and Handel (2013), this analysis was based on evaluations of whether the worker performed a set of occupational tasks (for instance planning, educating, repairing) and not generic tasks (e.g., problem-solving tasks, repetitive tasks or absence of interactive tasks, fixing things by hand). Cassidy (2017) revealed trends in task usage between the two data collections, and whether individual characteristics affect individual and occupation-mean task usage. Also, he studied the relation between individual task use and income. The results confirm the basic findings of Autor and Handel (2013), with Cassidy (2017) emphasising the importance of individual-level task information for income in addition to occupation-mean task usage.

The analysis in this article is similar to these analyses, with three noteworthy differences. First, the data used in this article were collected in 2011-2012 and are thus much more recent than the data used in the study by Cassidy (2017). Second, this is the first study for Germany that also uses generic task information. Third, a factor that has not been discussed in these papers is whether differences in task usage within occupations result from workplace heterogeneity. Autor and Handel's study did not consider any characteristics other than human capital and demographics. Cassidy considered the hierarchical level and controls for industry in the task models. One of the advantages of the more recent German task is that it also contains valuable information on workplace conditions, among them advances in technologies and computer programs in the workplace. In this article, it is explicitly tested whether task variance within occupations systematically relates to workplace differences, over and above individual characteristics. The analyses support this assumption.

The task-approach literature does not discuss whether the crucial task domains, i.e., abstract, routine and (non-routine) manual tasks, differ in the extent to which they are structured by occupations or to what extent differences in tasks are due to education and workplace characteristics. The results for Autor and Handel (2013) and Cassidy (2017) tend to show a higher explanatory contribution of occupations for manual tasks, but do not discuss this further. However, it is an interesting question whether analysing tasks as an occupation-level concept can be differently justified depending on the task domain. As stressed in the literature on occupational specificity, for individuals, it is important whether the skills in which they are particularly productive are only required in certain occupations or whether their career chances depend more on the specific job rather than the occupation. Comparing abstract, routine and non-routine manual tasks concerning their degrees of specificity this article argues that in Germany non-routine manual tasks are more occupation-specific than abstract or routine tasks. From this it is deduced that worker and workplace characteristics should explain less of the variance in non-routine manual tasks as compared to abstract and routine tasks, and that nonroutine manually skilled workers can certainly gain advantages from performing non-routine manual tasks in the German labour market, namely if they work in occupations which specialise in this field. Conforming to this argumentation, this article finds that variance in these manual tasks is much more explained by occupation than variance in abstract and routine tasks. Moreover, the results reveal that manually skilled workers earn higher wages for their skills in manual-specific occupations. In contrast, the analyses do not show any additional returns for highly abstract or routine tasks in abstract- or routine-intensive occupations.

This article makes four contribution to the literature. First, it is the first that uses generic task information to apply the Autor and Handel (2013) study to the German case. Second, it uses data that are more current than a similar study in Germany. Third, the article takes into ac- 
count workplace heterogeneity, as a factor that has not been systematically discussed and investigated so far. Finally, it considers that the three tasks domains differ systematically with regard to occupational specificity and tests empirical implications that can be derived from this.

The article proceeds as follows: Section 2 introduces the conceptual framework and derives hypotheses. Section 3 describes the data. The analytic strategy is described in Section 4. Section 5 presents results and Section 6 concludes.

\section{Conceptual Framework and Hypotheses}

The task approach draws an explicit distinction between skills, as characteristics of workers, and tasks, as characteristics of job requirements. One consequence of this distinction between skills and tasks is that the standard human capital model no longer provides a satisfactory approach for explaining returns to skills (Acemoglu \& Autor, 2011). Instead, this task-sensitive perspective is more compatible with a Roy model of occupational choice (Roy, 1951). In this model, individuals with different task efficiencies self-select into occupations that offer them the highest wages for their tasks. Occupations differ in the combination of different types of tasks and the extent and level to which these tasks are required and remunerated, or as Autor and Handel (2013, p. 65) put it, "the productive value of tasks differs among occupations". From a task-approach perspective, an occupation is conceptualised as an indivisible bundle of task demands that are performed simultaneously by each worker in the occupation in order to produce output (Autor \& Handel, 2013, p. 64). This implies that with regard to their job content, occupations should have a small within-variance and high between-occupation variance, i.e., that a substantial proportion of job task content is determined by occupations $(\mathrm{H} 1)$.

The task-approach literature does not discuss whether the crucial task domains, i.e., abstract, routine and non-routine manual tasks, differ in the extent to which they are structured by occupations. Research on occupational specificity argues that educational programs and occupations differ in the degree to which they relate to rather specific skills, i.e., skills that are immediately valuable within one occupation, or general skills, which are broad and transferable across occupations (see, e.g., Forster \& Bol, 2018). Eggenberger et al. (2018), for instance, define an occupation to be "specific" if the skills bundle of this occupation is very different from other occupations and "general" if it is similar to the skill bundles in many other occupations. A higher degree of specificity of skills is related to positive labour market outcomes, possibly because employers can use specifically-skilled workers directly to increase productivity (or their certificate suggests low training costs; cf. Forster \& Bol, 2018). Accordingly, one can also ask whether certain types of tasks are rather concentrated in specific occupations and hardly needed in others, while others occur in a similar way in different occupations. Comparing the three types of tasks typically distinguished in the task-approach literature, the conclusion is relatively easy to reach that non-routine manual tasks have a higher degree of occupational specificity than the other two task domains. Non-routine manual tasks involve manual dexterity, physical strength or physical effort. For example, mechanics, construction workers, carpenters and nurses typically perform these tasks. In Germany, most of these non-routine manual-intensive occupations are linked with highly standardised vocationspecific curricula of training occupations. Characteristic of these occupations is that task requirements are more or less fixed by very specific occupational regulations. Access to these occupations is reserved to those who have the appropriate certificates (for a comprehensive description of the German vocational education and training system see Solga, Protsch, Ebner, \& Brzinsky-Fay, 2014). All of these characteristics apply less to abstract, i.e., analytic, problem-solving tasks, or short repetitive, manual and cognitive routine tasks. Both do not relate to specific occupational profiles, and routine-intense occupations often have even no entry requirements, i.e., general or specific education. Altogether, one can deduce that non-routine manual tasks have a higher degree of specificity than abstract and routine tasks. If this assumption holds, the proportion of job task content, which is determined by occupations, should be larger in case of non-routine manual task content than in case of abstract or routine task content $(\mathrm{H} 2)$.

From a methodological point of view, obviously, the higher the level of aggregation of occupational information, the higher the level of imprecision, and thus the more within-occupational variance in job tasks should be observable. From a substantive position, the Roy model is compatible with systematic differences in task requirements within detailed occupations: exogenous changes in technology or workplace organisation affect workers within the same occupations at different workplaces to a different extent or, at least, at different points in time. Naturally, some workplaces (or firms) are better equipped to implement changes in technology or workplace organisation than others do. For instance, in firms that change their remuneration systems or production technologies, task requirements and thus the returns to tasks should differ from firms that did not already adapt to these exogenous changes. Compatible with this view, several studies have shown that some firms pay higher wages than others do for equally skilled workers (see Card, Heining, \& Kline, 2013). Fixed effects for detailed occupations then cannot account for all systematic variance in tasks. It can therefore be expected that variance in tasks within occupations is also systematically related to workplace heterogeneity; an empirical implication is that workplace characteristics are correlated with task content conditional on occupation (H3).

Whereas this assumption should apply to all three task domains, nevertheless, on can assume that because 
credential requirements and task content in non-routine manual-intensive occupations are much more fixed than in abstract or routine-intensive occupations, the proportion of job task content, which is determined by occupations, should be larger in case of non-routine manual task content than in case of abstract or routine task content even if the composition of worker and workplace characteristics within occupations is controlled for (H4).

In a situation of (ongoing) self-selection into occupations and jobs within occupations, workers with a higher task efficiency should move to workplaces within occupations that offer higher rewards and adapt their skills to changing task requirements (Autor \& Handel, 2013). For example, consider a situation where a firm replaces some manual tasks by robots, and the worker adapts to this change by performing more, better-paid machinecontrolling tasks. We then should observe that human capital (most importantly education) should have a double effect in determining job task content, namely allocating workers to occupations and influencing their job tasks within occupations. This is what Autor and Handel (2013) found in their analysis of the US data. Similar sorting processes should take place in the German labour market as well, so the empirical implication will be tested that human capital (education) is correlated with task content unconditional and conditional on occupation (H5).

If substantial variance in job tasks within occupations is observable, this could still be the result of measurement error. As Autor and Handel (2013, pp. 81-82) argue, however, "if self-reported variation in job tasks is a robust predictor of wages, this would provide prima facie evidence that self-reported task variation is likely to be informative about job content even within occupations". Therefore, this article also analyses the association between tasks and wages. More specifically, it will be tested whether within-occupational task differences are robust predictors of wages (H6).

Systematic sorting moreover implies that returns to tasks are higher in occupations that have high occupation-level returns to these tasks (Autor \& Handel, 2013, pp. 66-70). I suppose that the argument of sorting into occupations applies in particular to non-routine manual tasks, because of their higher occupational specificity: access to and advancement opportunities in these manual-intensive occupations is reserved to those who have the appropriate certificates, i.e., certificates that reliably indicate the applicants' skills and thus their abilities in performing specific tasks. Also, from Lazear's model of specificity (Lazear, 2009), one can deduce that a higher degree of specificity implies higher productivity and thus wages in those occupations that correspond to these specific skills (cf. Eggenberger et al., 2018, pp. 98-99). Empirically this argument implies that the more an occupation specialises in non-routine manual tasks, the higher should be the return to this task at the worker level. I will test whether there is a wage premium for performing non-routine manual tasks in an occupation that specialises in this task domain, over and above wage differences resulting from individual-level task use and occupation-level task intensity (H7).

\section{Data}

The data used to test these assumptions come from the 2012 Task Survey collected by the Federal Institute for Vocational Education and Training (BIBB; Alda, RohrbachSchmidt, \& Tiemann, 2015). This survey contains generic job task information for a nationally representative employee sample of the German working population, excluding workers with further training degree as their highest level attained, with a total sample size of 4,356 employees. These employees also participated in the 2012 Employment Survey (Hall, Siefer, \& Tiemann, 2015a, 2015b) carried out by BIBB and the Federal Institute for Occupational Safety and Health (BAuA), so rich information from this survey of employees' human capital, socio-demographics and workplace characteristics can be considered in the analyses as well. The generic job task information relates to workers' current main job at the time of the follow-up interview. Main job information is available as occupational codes at the 5-digit level of the German classification of occupations (occupational types), 2010 edition (KIdB2010). In the data at hand, there are 617 distinct 5-digit occupations with at least one employee. In around $5 \%$ of all occupation-cases $\left(n_{j}=211\right)$ a 5-digit is represented only by one employee.

For the multivariate analyses, I use a consistent sample of cases with full information on generic tasks, education, occupation, workplace measures and wages (528 cases were dropped). As in Autor and Handel's study, in all analyses I only consider workers with age 18 to 64 (a further 68 cases were dropped). For identification, I restrict the sample to occupations with at least five cases per 5-digit occupational codes (712 cases were dropped). This leaves me with $n_{i}=3,048$ worker-level observations nested in $n_{j}=198$ occupations. The average number of cases within these 198 occupations is 15.5 , and the maximum number is 102 . The distribution of the number of occupations is right-skewed, and the median number of observations per occupation is 10. Except for a small number of occupations $(<10 \%)$, they include both cases with VET or a university degree and/or those with no degree. Compared to the total analysis sample, these cases represent $34 \%$ of all 5 -digit occupations but $81 \%$ of all workers. As a robustness check, I inspected whether results differ, if the sample is restricted to at least 20 cases per 5-digit codes. Results with these alternative selections do not substantially differ from those presented below (main regression tables based on this selection are provided in Annex, Tables A1 and A2).

The data include highly similar generic task information as in Autor and Handel (2013). As in Autor and Handel (2013, pp. 70-71), analyses concentrate on three broad dimensions motivated by the conceptual framework in Autor et al. (2003): abstract problem-solving 
tasks ("abstract tasks"); routine, codifiable cognitive and manual tasks that follow explicit procedures ("routine tasks"); and non-routine manual job tasks that require physical adaptability ("manual tasks"). As for the US data, respondents were asked how often a series of tasks were required at their job (daily, at least once a week, at least once a month, less frequently than once a month, never). I consider only those items that were included in the Autor and Handel's analysis in the same way or very similarly. Four items are used to identify abstract tasks, i.e., (1) reading texts of 25 pages or longer, (2) using higher mathematics such as integral calculus or inference statistics, (3) the frequency of difficult problem-solving tasks, and (4) analysing. As in Autor and Handel (2013), items are combined into a standardised scale of abstract tasks using the first component of a principal component analysis. The component accounts for $60 \%$ of their variation; in Autor and Handel (2013) it was 42\%. For identifying jobs with routine tasks the following items are used: (1) performing short, repetitive tasks, and items for low interactive task content, i.e., the reversed items, (2) interacting with people other than colleagues, i.e., customers, clients, patients, schoolchildren or the public, (3) advising other people, and (4) interactions with applicants, candidates. Also, the items are combined into a standardised scale of routine tasks using the first component of a principal component analysis, which accounts for $42 \%$ of their variation (56\% in Autor \& Handel, 2013). For nonroutine manual tasks, I use: (1) using physical strength or making great physical effort and (2) using dexterity and manual skill (the first component explaining $68 \%$ of their variation; these two single tasks were included in one questionnaire item in Autor \& Handel, 2013). In some analyses, the mean occupational task usage of workers within occupations is considered as well.
Table 1 presents summary statistics of the explanatory and dependent variables used in the analyses presented in this article. Some other control variables are introduced in Section 4.

As in the German workforce, most individuals (65.9\%) in the sample have, as their highest vocational attainment, apprenticeship training or a full-time school vocational training degree (VET degree), $25.4 \%$ have a university degree (this includes degrees from universities of applied sciences) and $8.6 \%$ have no qualifying vocational degree. Females form $48.9 \%$ of the sample, and $9.8 \%$ have an immigrant background (non-German mother language and/or nationality other than German). Mean gross monthly wages (in euro) is 2,896 , the mean log hourly wage is 2.74 , and individuals in the sample have, on average, 23.9 years of labour market experience. $30.8 \%$ have a supervisory position. Substantial shares of employees state that they experienced the introduction of new manufacturing technologies or process technologies $(34.6 \%)$, or the introduction of new computer programs $(46.2 \%)$, or an increase in skill requirements (49.2\%) in their immediate working environment within the last two years. Average firm size (imputed by taking the midpoint of their firm size category) is 354 .

Table 2 presents the means and standard deviations of the composite task scales by major demographic groups, with basic patterns being highly similar in Germany and the US (see Autor \& Handel, 2013). The gap between workers without a degree and university graduates is about one standard deviation for abstract tasks and about two-thirds for non-routine manual and routine tasks. Routine tasks are the most important domain for workers without a degree, non-routine manual job tasks for workers with a VET degree and abstract tasks for those with a university degree.

Table 1. Sample summary statistics. Source: BIBB/BAuA Employment Survey 2012 and Supplemental Task Survey to the Employment Survey 2012, weigted by sampling weight.

\begin{tabular}{lll}
\hline & Mean & SD \\
\hline Highest voc. degree attained: & & 0.281 \\
No voc. degree & 0.086 & 0.474 \\
VET degree & 0.659 & 0.436 \\
$\quad$ University degree & 0.254 & 0.500 \\
Female & 0.489 & 0.297 \\
Immigrant background & 0.098 & 1886 \\
Gross monthly wage & 2896 & 0.507 \\
Log hourly wage & 2.74 & 10.8 \\
Experience in yrs. & 23.9 & 0.462 \\
\hline At workplace: & & 0.476 \\
$\quad$ Supervisory position & 0.308 & 0.499 \\
New technologies & 0.346 & 0.500 \\
New computer programs & 0.462 & 526.9 \\
Increase in skill requirements & 0.492 & 353.9 \\
\hline$N$ & 3,048 & \\
\hline
\end{tabular}


Table 2. Means and standard deviations (in parentheses) for standardized task scales by major demographic and education groups. Source: BIBB/BAuA Employment Survey 2012 and Supplemental Task Survey to the Employment Survey 2012.

\begin{tabular}{|c|c|c|c|c|c|c|c|c|}
\hline & \multirow[t]{2}{*}{ All } & \multirow[t]{2}{*}{ Male } & \multirow[t]{2}{*}{ Female } & \multicolumn{2}{|c|}{$\begin{array}{l}\text { Immigrant } \\
\text { Background }\end{array}$} & \multirow[t]{2}{*}{$\begin{array}{c}\text { No voc. } \\
\text { degree }\end{array}$} & \multirow[t]{2}{*}{ VET degree } & \multirow[t]{2}{*}{$\begin{array}{c}\text { University } \\
\text { degree }\end{array}$} \\
\hline & & & & yes & no & & & \\
\hline \multirow[t]{2}{*}{ Abstract } & .00 & .22 & -.17 & -.11 & .01 & -.58 & -.21 & .60 \\
\hline & $(1.00)$ & $(1.01)$ & $(0.96)$ & (1.11) & (0.99) & (1.14) & $(0.94)$ & $(0.82)$ \\
\hline \multirow[t]{2}{*}{ Routine } & .00 & .13 & -.10 & .15 & -.01 & .38 & .11 & -.35 \\
\hline & $(1.00)$ & $(1.02)$ & (0.97) & (0.99) & $(1.00)$ & $(0.94)$ & $(1.02)$ & $(0.87)$ \\
\hline \multirow[t]{2}{*}{ Non-routine Manual } & .00 & .06 & -.04 & .06 & -.01 & .22 & .18 & -.46 \\
\hline & $(1.00)$ & $(1.01)$ & (0.99) & $(0.97)$ & $(1.00)$ & (0.93) & $(0.97)$ & $(0.95)$ \\
\hline
\end{tabular}

Note: $\mathrm{N}=3,048$.

\section{Analytic Strategy}

The analyses proceed in two steps. First, variance in tasks and their determinants are analysed. Second, the association between tasks and wages is studied.

\subsection{Task Models}

The standardised task scales are regressed on demographics, human capital measures, workplace characteristics and occupation dummies, as follows:

$$
T_{i j}=\alpha+\beta_{1} S_{i}+\beta_{2} X_{i}+\beta_{3} W_{i}+\gamma_{j}+\varepsilon_{i j}
$$

where $T_{i j}$ is a vector of job tasks demands $T$ (abstract, routine, non-routine manual) of worker $i$ in occupation $j$. The vector $S$ includes human capital measures, i.e., the highest vocational degree attained and labour market experience in years and its square (mean-centered). $X$ is a vector of socio-demographic characteristics (gender, immigrant background). $W$ is a vector of workplace characteristics, including supervisory position, firm size (divided by 100 , mean-centered) and the three measures of the workplace environment as described above, as well as the firms' economic sector ( $28.3 \%$ public, $21.2 \%$ industry, $8.2 \%$ craft, $12.3 \%$ trade and commerce, $23.8 \%$ other services, and $6.2 \%$ trade unions, interest groups, and others) and whether the firm is located in the western $(85.7 \%)$ or eastern part of Germany (14.3\%) as additional controls.

Each task model is estimated with and without $\gamma$, a vector of 198 occupational dummies (one omitted). Because fixed-effects regression controls for unobserved occupational effects but not additional withinoccupation correlation, I use cluster-robust standard errors. With these specifications, it is tested whether tasks vary within occupations because of workplace heterogeneity (H3) and whether human capital (education) is correlated with task content unconditional and conditional on occupation (H5).

$\mathrm{H} 1$ states that a substantial proportion of job task content is determined by occupations. $\mathrm{H} 2$ states that the proportion of job task content determined by occupations should be larger in the case of non-routine manual tasks than in the case of abstract or routine tasks. If these assumptions hold, occupations (vector $\gamma$ ) should be a measurable predictor of job tasks, especially in the case of non-routine manual tasks. To test these hypotheses more directly, the intra-class-correlation (ICC) of an empty random intercept model of tasks (which is a random-effects analysis of variance [ANOVA]) is calculated. The ICC gives the fraction of occupation-level variance in $T_{i j}$ in total variance, by separating the variance in $T_{i j}$ into the variance between occupations and the variance within occupations, as follows:

$$
\mathrm{ICC}=\sigma_{u 0 j}^{2} / \sigma_{u 0 j}^{2}+\sigma^{2} \varepsilon_{i j}
$$

If it applies that non-routine manual tasks are much more structured by occupations ( $\mathrm{H} 2)$, then we should expect a higher ICC for non-routine manual tasks than for abstract or routine tasks in an empty model specification (see equation 3). $\mathrm{H} 4$ states that the proportion of job task content, which is determined by occupations, should be larger in case of non-routine manual task content even if the composition of worker and workplace characteristics within occupations is controlled for. To test this assumption, random intercept models of tasks with vectors $S, X$, and $W$ are calculated (see equation 4; because effect coefficients are not discussed, only the ICC-values are presented in Section 5).

$$
\begin{gathered}
T_{i j}=\gamma_{00}+u_{0 j}+\varepsilon_{i j} \\
T_{i j}=\gamma_{00}+\gamma_{10} S_{i j}+\gamma_{20} X_{i j}+\gamma_{30} W_{i j}+u_{0 j}+\varepsilon_{i j}
\end{gathered}
$$

\subsection{Wage Models}

In a second step, the wage-related hypotheses are tested. The OLS regression of log hourly wages have the form:

$$
W_{i j}=\alpha+\beta_{1} T_{i}+\beta_{2} S_{i}+\beta_{3} X_{i}+\beta_{4} W_{i}+\gamma+\varepsilon_{i j}
$$

where $W_{i j}$ are log hourly wages, $T_{i j}$ is a vector of job task demands $T$ (abstract, routine, non-routine manual, mean centred), and the vectors $S, X, W$ and $\gamma$ are as in the task models (see Section 4.1). Because of self-selection, occupations have to be treated as endogenous in wage equations (Chaparro, 2016, p. 4); as was discussed before, workers non-randomly self-select into occupations based on their task efficiency, leading to a positive correlation between, for example, education and the error term at the occupation level. The FE-approach with oc- 
cupation fixed effects can be used to obtain unbiased estimates of the within-occupation wage effects of tasks. Again, to account for within-occupational error correlations, I use standard errors clustered at the occupation level. Using this specification, it is tested whether individual job tasks are robust predictors of wages (H6).

$\mathrm{H} 7$ states that there is a wage premium for performing non-routine manual tasks in an occupation that specialises in this task, over and above wage differences resulting from individual-level task use and occupationlevel task intensity. In the presence of level-2 endogeneity (a correlation of covariates with the unobserved occupation effect), the random-effects estimation of such interaction effects might be inconsistent. The HausmanTaylor (HT) estimator instead provides valid standard errors and can handle the problem of occupation-level endogeneity (see Castellano, Rabe-Hesketh, \& Skrondal, 2014, for an application using student data nested in schools). The HT estimation takes advantage of the fixedeffects model (i.e., removing the heterogeneity bias) while retaining the ability to identify the parameters of the occupation-level variables. It is based upon an instrumental variable estimator that uses both the between and within variation of the exogenous variables as instruments, as follows:

$$
W_{i j}=X 1_{i j} \beta_{1}+X 2_{i j} \beta_{2}+Z 1_{j} d_{1}+Z 2_{j} d_{2}+Z 1_{j} X_{i j} \beta_{3}+u_{j}+\varepsilon_{i j}
$$

where $X 1$ are worker-level variables, among them job task demands and workplace variables, and $Z 1$ are occupationlevel variables assumed to be uncorrelated with $u_{j}+\varepsilon_{i j}$; and $X 2$ are worker-level variables and $Z 2$ occupation-level variables possibly correlated with $u_{j}$ but uncorrelated with $\varepsilon_{i j}$. In the application at hand, $X 2$ includes education, gender, and social background using the EriksonGoldthorpe-Portocarero class scheme (see Erikson \& Goldthorpe, 2002) based on parents' occupation and employment status. $Z 2$ includes two occupation variables that capture the educational composition in the occupation: the percentage share of workers in the occupation with vocational training and with university education, as their highest education (both grand-mean centred). The term $Z 1_{j} X_{i j}$ interacts each job task demand with the occupation-mean task usage. I tested whether the level-1 variables assumed to be level- 2 endogenous have enough within variance to serve as their own instrument. The exogenous level-1 variables (tasks) also correlate sufficiently strongly with the endogenous level-2 variables. A formal test of overidentifying restrictions (orthogonality conditions) reveals that the instruments may be valid, i.e., the Sargan-Hansen test statistic is not statistically significant.

\section{Results}

\subsection{Explaining Differences in Job Tasks: Education, Demographics and Workplace Measures}

Table 3 below presents results of the models of abstract, routine and non-routine manual tasks without (see mod- els M1) and with occupation-fixed effects (see models M2). As for the US, unconditional of occupation, there are statistically significant associations between tasks and education (the referent is VET), gender, and immigrant background: compared to VET graduates, unskilled workers perform fewer abstract tasks, but more routine tasks. In contrast, university graduates perform more abstract tasks, but fewer routine and non-routine manual tasks than VET graduates do. On average, females' use of all tasks is below that of males, possibly indicating that they specialise less in all task domains than males, whereas there are no differences across workers with and without an immigrant background. Experience is negatively related to routine and non-routine manual task intensity. In addition, workplace characteristics covary significantly with individual task usage. Workers with a supervisory position perform more abstract and non-routine manual tasks, but fewer routine tasks than workers with no such responsibility. If new technologies have been introduced at their workplace, these workers perform significantly more routine and manual tasks than comparable workers without such changes in their working environment. The introduction of new computer programs and increases in skill requirements instead are positively related to abstract task use but negatively related to routine tasks (as manual tasks with regards to new computer programs). Firm size is positively associated with routine tasks and negatively related to manual tasks.

Are these effects fully mediated by selection into occupations? As models M2 for each task domain show, while the size of coefficients clearly declines, human capital as well as most workplace characteristics remain significant predictors of abstract and non-routine manual job task use even within occupations. As the F-statistic in the lower part of the table shows, both groups of variables are jointly significant. This is a remarkable result if one considers that it is controlled for occupations at the 5-digit level of occupations in Germany: having completed university education instead of VET still is a significant positive correlate for abstract tasks, and negative correlate for non-routine manual tasks. These results show that as in the US, education plays a dual role in determining workers' job tasks, namely allocating them to occupations and influencing their job tasks within occupations (i.e., H5). The results also reveal significant withinoccupation effects of workplace measures. The effects on abstract and routine tasks are usually smaller but remain significant in nearly all cases. Concerning non-routine manual tasks, the negative effect of new computer programs at the workplace is fully mediated by occupations, and workers who experience an increase in skill requirements at their workplace perform significantly more nonroutine manual tasks. These results support the assumption that workplace characteristics are correlated with task content conditional on occupation ( $\mathrm{H} 3)$, suggesting that some differences in task content within occupations are related to workplace heterogeneity. 
The results in Table 3 also reveal that occupation is an important measurable determinant of job task content. Conditioning on occupations, in most cases, strongly attenuates the coefficients and the explanatory power increases substantially. Comparing the predictive power across task domains shows that occupations do a different job in determining job tasks. Occupations account for up to $52 \%$ of variance in non-routine manual tasks in the FE-model (M2), but only $44 \%$ and $41 \%$ for abstract and routine tasks, respectively. Also, the gain compared to models without fixed occupational effects (M1) is significantly higher for non-routine manual tasks $(+37 \%)$ than for abstract $(+16 \%)$ and routine tasks $(+22 \%)$.

To further analyse whether and to what extent variance in tasks results from differences across and within occupations, Table 4 includes the results of the randomeffects ANOVA. In the empty model specification, the fraction of variance at the occupation-level (ICC) is $37.9 \%$ for abstract tasks, $34.7 \%$ for routine tasks and $46.6 \%$ for non-routine manual tasks. It is $23.1 \%, 25.8 \%$ and $42 \%$, respectively, if the composition concerning human capital, demographic and workplace-related characteristics are controlled for. Thus, non-routine manual tasks are the domain with the largest amount of variance that results from differences between occupations (and thus the lowest fraction of variance that results from differences within occupations), and this also holds true if compositional effects are considered. As column 4 in table 4 reveals, the reduction of error variance at the occupation-level is much smaller in case of non-routine manual tasks (i.e., $-9.9 \%$ ) than in case of abstract and routine tasks $(-39.1 \%$ and $-25.6 \%)$. Taken together, the results show that indeed a substantial proportion of job task content is determined by occupations (H1). Possi-

Table 3. OLS-Regressions of abstract, routine, and non-routine manual tasks without/with occupation fixed effects. Source: BIBB/BAuA Employment Survey 2012 and Supplemental Task Survey to the Employment Survey 2012.

\begin{tabular}{|c|c|c|c|c|c|c|}
\hline & \multicolumn{2}{|c|}{ Abstract } & \multicolumn{2}{|c|}{ Routine } & \multicolumn{2}{|c|}{ Non-Routine Manual } \\
\hline & M1 & $\mathrm{M} 2$ & M1 & M2 & M1 & M2 \\
\hline \multicolumn{7}{|l|}{ Highest voc. educ. (R. VET): } \\
\hline \multirow[t]{2}{*}{ No voc. degree } & $-0.26 * * *$ & -0.06 & $0.22 * *$ & 0.05 & 0.05 & -0.01 \\
\hline & $(0.06)$ & $(0.06)$ & $(0.07)$ & $(0.07)$ & $(0.07)$ & $(0.07)$ \\
\hline \multirow[t]{2}{*}{ University degree } & $0.64 * * *$ & $0.15^{* * *}$ & $-0.32 * * *$ & -0.02 & $-0.62 * * *$ & $-0.19 * * *$ \\
\hline & $(0.04)$ & $(0.04)$ & $(0.04)$ & $(0.05)$ & $(0.04)$ & $(0.05)$ \\
\hline \multirow[t]{2}{*}{ Female } & $-0.36 * * *$ & $-0.33^{* * *}$ & $-0.12^{* * *}$ & $0.09 *$ & $-0.16^{* * *}$ & $-0.11^{* *}$ \\
\hline & $(0.03)$ & $(0.04)$ & $(0.04)$ & $(0.04)$ & $(0.04)$ & $(0.04)$ \\
\hline \multirow[t]{2}{*}{ Immigrant background } & -0.09 & 0.03 & 0.08 & -0.04 & 0.04 & $-0.09 *$ \\
\hline & $(0.06)$ & $(0.06)$ & $(0.06)$ & $(0.06)$ & $(0.06)$ & $(0.04)$ \\
\hline \multirow[t]{2}{*}{ Experience } & 0.00 & 0.01 & $-0.02 *$ & $-0.01^{*}$ & $-0.01^{*}$ & -0.01 \\
\hline & $(0.01)$ & $(0.01)$ & $(0.01)$ & $(0.01)$ & $(0.01)$ & $(0.01)$ \\
\hline \multirow[t]{2}{*}{ Experience $^{2}$} & -0.00 & -0.00 & $0.00^{*}$ & $0.00^{*}$ & $0.00^{+}$ & 0.00 \\
\hline & $(0.00)$ & $(0.00)$ & $(0.00)$ & $(0.00)$ & $(0.00)$ & $(0.00)$ \\
\hline \multicolumn{7}{|l|}{ At workplace: } \\
\hline \multirow[t]{2}{*}{ Supervisory position } & $0.24 * * *$ & $0.20 * * *$ & $-0.35 * * *$ & $-0.26 * * *$ & $0.15^{* * *}$ & $0.11^{* *}$ \\
\hline & $(0.03)$ & $(0.04)$ & $(0.04)$ & $(0.04)$ & $(0.04)$ & $(0.04)$ \\
\hline \multirow[t]{2}{*}{ New technologies } & -0.02 & 0.04 & $0.08^{*}$ & -0.01 & $0.23 * * *$ & $0.10 * *$ \\
\hline & $(0.04)$ & $(0.04)$ & $(0.04)$ & $(0.04)$ & $(0.04)$ & $(0.03)$ \\
\hline \multirow[t]{2}{*}{ New computer programs } & $0.27^{* * *}$ & $0.16^{* * *}$ & $-0.16 * * *$ & $-0.09 *$ & $-0.20 * * *$ & 0.02 \\
\hline & $(0.03)$ & $(0.04)$ & $(0.03)$ & $(0.04)$ & $(0.04)$ & $(0.03)$ \\
\hline \multirow[t]{2}{*}{ Increase in skill requir. } & $0.30 * * *$ & $0.20 * * *$ & $-0.22 * * *$ & $-0.12^{* * *}$ & 0.03 & $0.07^{*}$ \\
\hline & $(0.03)$ & $(0.03)$ & $(0.03)$ & $(0.03)$ & $(0.03)$ & $(0.03)$ \\
\hline \multirow[t]{2}{*}{ Firm size } & 0.00 & 0.00 & $0.01 * *$ & $0.01 * * *$ & $-0.02 * * *$ & $-0.01 * * *$ \\
\hline & $(0.00)$ & $(0.00)$ & $(0.00)$ & $(0.00)$ & $(0.00)$ & $(0.00)$ \\
\hline \multirow[t]{2}{*}{ Constant } & -0.07 & -0.03 & $0.35 * * *$ & $0.21^{*}$ & $0.59 * * *$ & $0.23^{* *}$ \\
\hline & $(0.09)$ & $(0.09)$ & $(0.09)$ & $(0.09)$ & $(0.10)$ & $(0.08)$ \\
\hline 198 occupation dummies & No & Yes & No & Yes & No & Yes \\
\hline F(Education) & $175.19 * * *$ & $5.87 * *$ & $43.72 * * *$ & 0.43 & $125.89 * * *$ & $9.68 * * *$ \\
\hline F(Workplace variables) & $34.60 * * *$ & $12.60 * * *$ & $40.23^{* * *}$ & $5.12 * * *$ & $20.48 * * *$ & $11.25 * * *$ \\
\hline F(Occupation dummies) & & $4.32 * * *$ & & $11.33^{* * *}$ & & $6.37^{* * *}$ \\
\hline R-squared & 0.28 & 0.44 & 0.19 & 0.41 & 0.15 & 0.52 \\
\hline $\mathrm{N}$ & 3048 & 3048 & 3048 & 3048 & 3048 & 3048 \\
\hline
\end{tabular}

Notes: All models control for firm location and economic sector; $+p<0.10, * p<0.05, * * p<0.01, * * * p<0.001$. 
Table 4. ICCs for random intercept models of job tasks. Source: BIBB/BAuA Employment Survey 2012 and Supplemental Task Survey to the Employment Survey 2012.

\begin{tabular}{lccc}
\hline & ICC M0 & ICC M1 & Change ICC in \% \\
\hline Abstract & .379 & .231 & $-39,1$ \\
Routine & .347 & .258 & $-25,6$ \\
Non-Routine Manual & .466 & .420 & -9.87 \\
\hline $\mathrm{N}_{\text {(occupation) }}$ & 198 & 198 & \\
\hline $\mathrm{N}_{\mathrm{i} \text { (workers) }}$ & 3048 & 3048 & \\
\hline
\end{tabular}

Notes: M0 includes no predictor variables. M1 controls for worker and workplace composition, i.e., education, gender, experience, experience squared, immigrant background; and supervisory status, firm size, new manufacturing/process technologies, new computer programs, increases in skill requirements, economic sector, firm location (West/East-Germany).

bly, because of their higher occupational specificity, nonroutine manual task content is especially bound to occupations $(\mathrm{H} 2)$, even if worker and workplace characteristics are controlled for $(\mathrm{H} 4)$. Yet the results also show that worker and workplace characteristics substantially correlate with job task content over and above occupations.

\subsection{Job Tasks and Wages}

Table 5 shows the results of the wage models. Model M1 only includes the individual-level task scales. These scales predict substantial wage differences. A one standard deviation increase of the abstract tasks scale is as-

Table 5. OLS and Hausman-Taylor regressions of Log Hourly Wages on Task Scales. Source: BIBB/BAuA Employment Survey 2012 and Suppl. Task Survey to the Employment Survey 2012.

\begin{tabular}{|c|c|c|c|c|c|c|}
\hline & M1 & M2 & M3 & M4 & M5 & M6 \\
\hline Abstract (worker level) & $\begin{array}{l}0.17^{* * *} \\
(0.01)\end{array}$ & $\begin{array}{l}0.08 * * * \\
(0.01)\end{array}$ & $\begin{array}{c}0.03^{* *} \\
(0.01)\end{array}$ & & $\begin{array}{c}0.02 * * \\
(0.01)\end{array}$ & $\begin{array}{c}0.03 * * \\
(0.01)\end{array}$ \\
\hline Routine (worker level) & $\begin{array}{c}0.02 \\
(0.01)\end{array}$ & $\begin{array}{c}-0.01 \\
(0.01)\end{array}$ & $\begin{array}{c}0.00 \\
(0.01)\end{array}$ & & $\begin{array}{c}0.00 \\
(0.01)\end{array}$ & $\begin{array}{c}0.01 \\
(0.01)\end{array}$ \\
\hline Non-Routine Manual (worker level) & $\begin{array}{c}-0.12 * * * \\
(0.01)\end{array}$ & $\begin{array}{l}-0.08^{* * *} \\
(0.01)\end{array}$ & $\begin{array}{l}-0.04^{* * *} \\
(0.01)\end{array}$ & & $\begin{array}{c}-0.04 * * * \\
(0.01)\end{array}$ & $\begin{array}{c}-0.04^{* * *} \\
(0.01)\end{array}$ \\
\hline Abstract (occup. level) & & & & $\begin{array}{l}0.23^{* * *} \\
(0.03)\end{array}$ & $\begin{array}{l}0.21^{* * *} \\
(0.03)\end{array}$ & $\begin{array}{c}0.17^{*} \\
(0.07)\end{array}$ \\
\hline Routine (occup. level) & & & & $\begin{array}{c}-0.00 \\
(0.02)\end{array}$ & $\begin{array}{c}-0.00 \\
(0.02)\end{array}$ & $\begin{array}{c}0.01 \\
(0.03)\end{array}$ \\
\hline Non-Routine Manual (occup. level) & & & & $\begin{array}{c}-0.08^{* * *} \\
(0.02)\end{array}$ & $\begin{array}{c}-0.04^{*} \\
(0.02)\end{array}$ & $\begin{array}{c}-0.04 \\
(0.03)\end{array}$ \\
\hline $\begin{array}{l}\text { Abstract (worker level) } \\
* \text { Abstract (occup. level) } \\
\text { Routine (worker level) } \\
\text { * Routine (occup. level) } \\
\text { Non-Routine Manual (worker level) } \\
\text { * Non-Routine Manual (occup. level) }\end{array}$ & & & & & & $\begin{array}{c}-0.00 \\
(0.01) \\
0.01 \\
(0.01) \\
0.03^{*} \\
(0.02)\end{array}$ \\
\hline Worker-/workplace controls & No & Yes & Yes & Yes & Yes & Yes \\
\hline 198 occupation dummies & No & No & Yes & No & No & - \\
\hline Constant & $\begin{array}{l}2.75^{* * *} \\
(0.02)\end{array}$ & $\begin{array}{l}2.59 * * * \\
(0.03)\end{array}$ & $\begin{array}{l}2.62 * * * \\
(0.03)\end{array}$ & $\begin{array}{l}2.59 * * * \\
(0.03)\end{array}$ & $\begin{array}{l}2.60 * * * \\
(0.03)\end{array}$ & $\begin{array}{l}2.56^{* * * *} \\
(0.04)\end{array}$ \\
\hline F(Task variables) & $88.90 * * *$ & $47.81 * * *$ & $10.10 * * *$ & & $9.69 * * *$ & $21.24 * * *$ \\
\hline F(Occ-lev. Task var) & & & & $64.91 * * *$ & $34.26 * * *$ & $8.01^{*}$ \\
\hline R-squared & 0.18 & 0.37 & 0.48 & 0.40 & 0.40 & - \\
\hline $\mathrm{N}$ & 3048 & 3048 & 3048 & 3048 & 3048 & 2738 \\
\hline
\end{tabular}

Notes: Worker controls are education, gender, experience, experience squared, immigrant background. Workplace controls are supervisory status, firm size, new manufacturing/process technologies, new computer programs, increases in skill requirements, economic sector, firm location (West/East-Germany). M6 add. includes social background, \%share of VET/univ. graduates in the occupation. Robust standard errors in parentheses; $+p<0.10, * p<0.05, * * p<0.01, * * * p<0.001$. 
sociated with an approximate $17 \%$ wage premium, while similar increases in non-routine manual tasks are associated with a $12 \%$ wage penalty. Effect sizes thus are highly similar to those found in the US (i.e., $+20 \%$ and $-19 \%$, respectively; see Autor \& Handel, 2013, p. 82). In this model, there is no systematic association between routine tasks and wages in Germany (in the US, routine tasks also loose significance in models with controls for human capital or occupational dummies). By themselves, the three generic task scales explain $18 \%$ of wage variation. $\mathrm{M} 2$ additionally controls for education, experience, gender, immigrant status and the full set of workplace characteristics, and M3 additionally includes occupation-fixed effects. Even though the magnitude of the task coefficients decline, abstract and non-routine manual tasks remain significant correlates of wages in both models. In model M4 only the occupational-level task variables are included. When tasks are measured at the occupation-level again abstract and non-routine manual tasks are significant predictors of wages as well. In model M5 both, individual and occupation-level tasks are included (as well as worker and workplace controls). This model is in line with the finding reported in Cassidy (2017, p. 408) that job tasks at the individual level are informative about wages even if the task content at the occupational level is controlled for. That job tasks have a partial effect on wages is also reflected in the highly significant F-statistics. Altogether, these findings argue strongly that within-occupational task differences are robust predictors of wages $(\mathrm{H} 6)$.

Model M6 is the Hausman-Taylor specification, which tests whether there is a wage premium for performing non-routine manual tasks in an occupation that specialises in this task domain, over and above wage differences resulting from individual-level task use and occupation-level task intensity. For non-routine manual tasks, the results are compatible with systematic sorting into occupations: remarkably, while the main effects of non-routine manual tasks are (significantly) negative, the interaction term is positive, statistically significant and of substantial size. This effect is stable, even if other interaction terms are included and even conditional on educational attainment and further worker and workplace characteristics. This supports the interpretation that manually skilled workers can generate positive returns on their skills in their specific fields of activity (H7). In contrast, the analyses do not show any additional returns for highly abstract or routine tasks in abstract- or routine-intensive occupations.

\section{Conclusions}

On the one hand, recent findings have demonstrated that technological changes throughout recent decades have differently influenced the demand for several types of skills with advantages for highly qualified employees in abstract-intensive occupations, i.e., occupations that require large numbers of analytic, problem-solving tasks.
On the other hand, recent studies have stressed that occupation-specific skills provide benefits in the labour market, at least for those with a view to early entry into the labour market.

Using worker-level data from Germany in 2011-2012, this article analysed the association between education and generic job task requirements, and between job tasks and wages, while assuming that the three main task domains distinguished in the literature differ in their level of occupational specificity. It was argued that nonroutine manual tasks have a higher degree of specificity than abstract and routine tasks.

There are four main findings in this article. First, while in fact a large part of generic job content is determined by occupations, job task requirements also differ systematically within occupations with workers' educational levels and workplace characteristics. Having completed university education instead of VET education is a significant positive correlate for abstract tasks, and a negative correlate for non-routine manual tasks, even within detailed occupational groups. A supervisory position, increases in skill requirements, new manufacturing or process technologies and new computer programs at the workplace are positively related to abstract and non-routine manual task usage. Second, differences in task usage within occupations are robust predictors of wage differences between workers. Conforming to the previous literature, on average, abstract task usage is positively related to wages, whereas non-routine manual task usage is related to lower wages. Third, the results support the view that non-routine manual tasks have a higher occupational specificity than abstract and routine tasks. This conclusion is based on the observation that occupations have a higher predictive power for this type of task, and that compared to abstract and routine tasks a higher share of variance in non-routine manual tasks results from differences across occupations. Analysing tasks as an occupation-level concept, in Germany, might be therefore better justified for non-routine manual than for abstract routine tasks. Fourth, results of a Hausman-Taylor regression model reveal a wage premium for non-routine manual task usage in non-routine manual-intensive occupations, but no such premium in case of abstract and routine tasks. This finding can be well rationalised by the concept of specificity, which implies higher productivity, and thus wages for workers with specific skills in those occupations that correspond to these skills.

Altogether, this article thus underlines the merits of a task-based approach and worker-level task information for understanding the interplay between education, tasks and wages. Second, it seems fruitful to consider the specificity of tasks in addition to the tasks as such. The results suggest that in areas with specialised task requirements, the value of specific skills is high and rewarded accordingly. For Germany, this can be seen in the area of non-routine manual tasks. While non-routine manual tasks, on average, tend to be associated with lower wages than abstract tasks, manu- 
ally skilled workers achieve wage gains in non-routine, manual-specific occupations.

Future research might advance these analyses in several respect. First, more differentiated distinctions between task domains, for instance factors of social, technical, creative, cognitive skills, as in Liu and Grusky (2013), could further deepen the occupation-level argumentation presented here. Second, this article, on a descriptive basis, indeed finds substantial within-occupation job tasks variance across workplaces, but the conceptual model did not include factors that determine this variance in a systematic or even causal way (see, e.g., Deming, 2017). Intensifying research on how workplace heterogeneity adds to the understanding of job task content and the returns to tasks seems a valuable direction for future research. Another limitation is that the analyses are based on a comparatively small cross-sectional sample. Future studies should strive to extend testing the model in other contexts and with more highly powered data, and individual panel data to further verify the robustness of the results.

\section{Acknowledgments}

Funding for this work has been provided by the German Federal Institute for Vocational Education and Training. Previous versions of this article were presented at the 4th International TASKS Conference, Mannheim, Germany, and the LIfBi, DGS, FiBuS, IAB Conference "Occupations and Social Inequality", Nuremberg, Germany. The author would like to thank the participants at these presentations, the editors and three anonymous reviewers for their valuable comments on earlier versions of the article.

\section{Conflict of Interests}

The author declares no conflict of interests.

\section{References}

Acemoglu, D., \& Autor, D. (2011). Skills, tasks and technologies: Implications for employment and earnings. In D. Card \& O. Ashenfelter (Eds.), Handbook of labor economics (Vol. 4, pp. 1043-1171). Amsterdam: Elsevier.

Alda, H., Rohrbach-Schmidt, D., \& Tiemann, M. (2015). $B I B B$ supplemental task survey to the employment survey 2012 (version 2). Bonn: Federal Institute for Vocational Education and Training. https://doi.org/ 10.7803/610.12.1.1.20

Allmendinger, J. (1989). Educational systems and labor market outcomes. European Sociological Review, 5(3), 231-250.

Antonczyk, D., DeLeire, T., \& Fitzenberger, B. (2018). Polarization and rising wage inequality: Comparing the US and Germany. Econometrics, 6(2), 1-33.

Autor, D., \& Dorn, D. (2013). The growth of low-skill ser- vice jobs and the polarization of the US labor market. American Economic Review, 103(5), 1553-1597.

Autor, D., \& Handel, M. J. (2013). Putting tasks to the test: Human capital, job tasks, and wages. Journal of Labor Economics, 31(2), 59-96.

Autor, D., Levy, F., \& Murnane, R. J. (2003). The skill content of recent technological change: An empirical exploration. The Quarterly Journal of Economics, 118(4), 1279-1333.

Card, D., Heining, J., \& Kline, P. (2013). Workplace heterogeneity and the rise of West German wage inequality. The Quarterly Journal of Economics, 128(3), 967-1015.

Cassidy, H. (2017). Task variation within occupations. Industrial Relations: A Journal of Economy and Society, 56(3), 393-410.

Castellano, K. E., Rabe-Hesketh, S., \& Skrondal, A. (2014). Composition, context, and endogeneity in school and teacher comparisons. Journal of Educational Behavioral Statistics, 39(5), 333-367.

Chaparro, J. (2016). Occupational choice and returns to skills: Evidence from the NLSY79 and $\mathrm{O}^{*} \mathrm{Net}$ (Unpublished Doctoral Dissertation). University of Minnesota.

de Lange, M., Gesthuizen, M., \& Wolbers, M. H. (2014). Youth labour market integration across Europe: The impact of cyclical, structural, and institutional characteristics. European Societies, 16(2), 194-212.

Deming, D. J. (2017). The growing importance of social skills in the labor market. The Quarterly Journal of Economics, 132(4), 1593-1640.

Eggenberger, C., Rinawi, M., \& Backes-Gellner, U. (2018). Occupational specificity: a new measurement based on training curricula and its effect on labor market outcomes. Labour Economics, 51, 97-107.

Erikson, R., \& Goldthorpe, J. H. (2002). Intergenerational inequality: A sociological perspective. Journal of Economic Perspectives, 16(3), 31-44.

Forster, A. G., \& Bol, T. (2018). Vocational education and employment over the life course using a new measure of occupational specificity. Social Science Research, 70, 176-197.

Goos, M., Manning, A., \& Salomons, A. (2014). Explaining job polarization: Routine-biased technological change and offshoring. American Economic Review, 104(8), 2509-2526.

Hall, A., Siefer, A., \& Tiemann, M. (2015a). BIBB/BAuA Employment survey of the working population on qualification and working conditions in Germany 2012 (suf_4.0). Bonn: Federal Institute for Vocational Education and Training. https://doi.org/10.7803/501. 12.1.1.40

Hall, A., Siefer, A., \& Tiemann, M. (2015b). BIBB/BAuA Employment survey of the working population on qualification and working conditions in Germany 2012 (sv_2.0). Bonn: Federal Institute for Vocational Education and Training. https://doi.org/10.7803/501. 12.1.5.20 
Hanushek, E. A., Schwerdt, G., Woessmann, L., \& Zhang, L. (2017). General education, vocational education, and labor-market outcomes over the lifecycle. Journal of Human Resources, 52(1), 48-87.

Lazear, E. P. (2009). Firm-specific human capital: A skill-weights approach. Journal of Political Economy, 117(5), 914-940.

Liu, Y., \& Grusky, D. B. (2013). The payoff to skill in the third industrial revolution. American Journal of Sociology, 118(5), 1330-1374.

Roy, A. D. (1951). Some thoughts on the distribution of earnings. Oxford Economic Papers, 3(2), 135-146.
Shavit, Y., \& Müller, W. (1998). From school to work. A comparative study of educational qualifications and occupational destinations. Oxford: Clarendon Press.

Solga, H., Protsch, P., Ebner, C., \& Brzinsky-Fay, C. (2014). The German vocational education and training system: Its institutional configuration, strengths, and challenges (WZB Discussion Paper no. 2014-502). Berlin: WZB.

Spitz-Oener, A. (2006). Technical change, job tasks, and rising educational demands: Looking outside the wage structure. Journal of Labor Economics, 24(2), 235-270.

\section{About the Author}

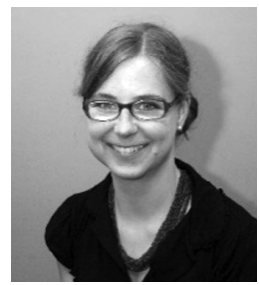

Daniela Rohrbach-Schmidt is a Postdoctoral researcher at the Research Data Centre of the German Federal Institute for Vocational Education and Training (BIBB), Bonn, Germany. She received her PhD in Sociology at the University of Cologne, Germany. Her research focuses on sociology of education and the labour market with particular focus on vocational education and training as well as occupations. 


\section{Annex}

Table A1. OLS-Regressions of abstract, routine, and non-routine manual tasks without/with occupation fixed effects for occupations with $n_{i} \geq 20$. Source: BIBB/BAuA Employment Survey 2012 and Supplemental Task Survey to the Employment Survey 2012.

\begin{tabular}{|c|c|c|c|c|c|c|}
\hline & \multicolumn{2}{|c|}{ Abstract } & \multicolumn{2}{|c|}{ Routine } & \multicolumn{2}{|c|}{ Non-Routine Manual } \\
\hline & M1 & $\mathrm{M} 2$ & M1 & $\mathrm{M} 2$ & M1 & $\mathrm{M} 2$ \\
\hline \multicolumn{7}{|l|}{ Highest voc. educ. (R. VET): } \\
\hline \multirow[t]{2}{*}{ No voc. degree } & $-0.42 * * *$ & $-0.17^{+}$ & $0.31^{* *}$ & 0.08 & 0.03 & -0.04 \\
\hline & $(0.10)$ & $(0.09)$ & $(0.10)$ & $(0.10)$ & $(0.10)$ & $(0.11)$ \\
\hline \multirow[t]{2}{*}{ University degree } & $0.56^{* * *}$ & $0.10^{*}$ & $-0.12 *$ & -0.07 & $-0.54 * * *$ & $-0.16^{* * *}$ \\
\hline & $(0.06)$ & $(0.05)$ & $(0.06)$ & $(0.08)$ & $(0.06)$ & $(0.07)$ \\
\hline \multirow[t]{2}{*}{ Female } & $-0.30 * * *$ & $-0.27 * * *$ & $-0.17^{* *}$ & 0.07 & $-0.14^{* *}$ & $-0.11^{*}$ \\
\hline & $(0.05)$ & $(0.06)$ & $(0.05)$ & $(0.07)$ & $(0.05)$ & $(0.05)$ \\
\hline \multirow[t]{2}{*}{ Immigrant background } & $-0.15^{+}$ & 0.05 & 0.12 & -0.02 & 0.02 & $-0.12^{+}$ \\
\hline & $(0.09)$ & $(0.08)$ & $(0.09)$ & $(0.09)$ & $(0.09)$ & $(0.06)$ \\
\hline \multirow[t]{2}{*}{ Experience } & -0.00 & 0.00 & -0.01 & -0.00 & -0.02 & -0.00 \\
\hline & $(0.01)$ & $(0.01)$ & $(0.01)$ & $(0.01)$ & $(0.01)$ & $(0.01)$ \\
\hline \multirow[t]{2}{*}{ Experience $^{2}$} & -0.00 & -0.00 & 0.00 & 0.00 & 0.00 & -0.00 \\
\hline & $(0.00)$ & $(0.00)$ & $(0.00)$ & $(0.00)$ & $(0.00)$ & $(0.00)$ \\
\hline \multicolumn{7}{|l|}{ At workplace: } \\
\hline \multirow[t]{2}{*}{ Supervisory position } & $0.23 * * *$ & $0.22 * * *$ & $-0.29 * * *$ & $-0.27 * * *$ & $0.20 * * *$ & 0.07 \\
\hline & $(0.05)$ & $(0.06)$ & $(0.06)$ & $(0.05)$ & $(0.06)$ & $(0.05)$ \\
\hline \multirow[t]{2}{*}{ New technologies } & 0.03 & 0.03 & 0.02 & -0.06 & $0.24 * * *$ & $0.09^{+}$ \\
\hline & $(0.05)$ & $(0.05)$ & $(0.06)$ & $(0.06)$ & $(0.06)$ & $(0.04)$ \\
\hline \multirow[t]{2}{*}{ New computer programs } & $0.22 * * *$ & $0.17 * * *$ & $-0.14 * *$ & -0.08 & $-0.19 * * *$ & 0.04 \\
\hline & $(0.05)$ & $(0.06)$ & $(0.05)$ & $(0.05)$ & $(0.05)$ & $(0.03)$ \\
\hline \multirow[t]{2}{*}{ Increase in skill requir. } & $0.31 * * *$ & $0.21 * * *$ & $-0.18 * * *$ & $-0.10^{*}$ & 0.03 & 0.03 \\
\hline & $(0.05)$ & $(0.04)$ & $(0.05)$ & $(0.04)$ & $(0.05)$ & $(0.04)$ \\
\hline \multirow[t]{2}{*}{ Firm size } & 0.00 & 0.00 & $0.01^{+}$ & $0.01^{*}$ & $-0.02 * * *$ & $-0.01 * * *$ \\
\hline & $(0.00)$ & $(0.01)$ & $(0.01)$ & $(0.01)$ & $(0.01)$ & $(0.00)$ \\
\hline \multirow[t]{2}{*}{ Constant } & 0.18 & 0.14 & 0.19 & 0.03 & $0.69 * * *$ & 0.18 \\
\hline & $(0.14)$ & $(0.13)$ & $(0.15)$ & $(0.11)$ & $(0.15)$ & $(0.12)$ \\
\hline 39 occupation dummies & No & Yes & No & Yes & No & Yes \\
\hline F(Education) & $68.54 * * *$ & $3.02 *$ & $7.92 * * *$ & 0.77 & $40.64 * * *$ & $3.41 *$ \\
\hline F(Workplace variables) & $18.72 * * *$ & $7.66 * * *$ & $17.07^{* * *}$ & $5.87 * * *$ & $9.97 * * *$ & $3.34 * * *$ \\
\hline F(Occupation dummies) & & $9.58^{* * *}$ & & $12.00 * * *$ & & $31.84 * * *$ \\
\hline R-squared & 0.26 & 0.41 & 0.16 & 0.36 & 0.13 & 0.52 \\
\hline $\mathrm{N}$ & 1525 & 1525 & 1525 & 1525 & 1525 & 1525 \\
\hline
\end{tabular}

Notes: All models control for firm location and economic sector; $+p<0.10, * p<0.05, * * p<0.01, * * * p<0.001$. 
Table A2. OLS and Hausman-Taylor regressions of Log Hourly Wages on Task Scales for occupations with $n_{i} \geq 20$. Source: BIBB/BAuA Employment Survey 2012 and Suppl. Task Survey to the Employment Survey 2012.

\begin{tabular}{|c|c|c|c|c|c|c|}
\hline & M1 & M2 & M3 & M4 & M5 & M6 \\
\hline \multirow[t]{2}{*}{ Abstract (worker level) } & $0.15 * * *$ & $0.08 * * *$ & $0.03 * *$ & & $0.03 * *$ & $0.03 * *$ \\
\hline & $(0.02)$ & $(0.01)$ & $(0.01)$ & & $(0.01)$ & $(0.01)$ \\
\hline \multirow[t]{2}{*}{ Routine (worker level) } & 0.02 & -0.01 & 0.00 & & 0.00 & 0.01 \\
\hline & $(0.01)$ & $(0.01)$ & $(0.01)$ & & $(0.01)$ & $(0.01)$ \\
\hline \multirow[t]{2}{*}{ Non-Routine Manual (worker level) } & $-0.12^{* * *}$ & $-0.09 * * *$ & $-0.05 * * *$ & & $-0.05^{* * *}$ & $-0.04 * * *$ \\
\hline & $(0.02)$ & $(0.01)$ & $(0.01)$ & & $(0.01)$ & $(0.01)$ \\
\hline \multirow[t]{2}{*}{ Abstract (occup. level) } & & & & $0.28 * * *$ & $0.26 * * *$ & $0.19 * *$ \\
\hline & & & & $(0.03)$ & $(0.03)$ & $(0.06)$ \\
\hline \multirow[t]{2}{*}{ Routine (occup. level) } & & & & 0.01 & -0.00 & 0.03 \\
\hline & & & & $(0.03)$ & $(0.04)$ & $(0.04)$ \\
\hline \multirow[t]{2}{*}{ Non-Routine Manual (occup. level) } & & & & $-0.09 * * *$ & -0.04 & $-0.06^{+}$ \\
\hline & & & & $(0.02)$ & $(0.02)$ & $(0.03)$ \\
\hline \multirow[t]{2}{*}{ Abstract (worker level)* Abstract (occup. level) } & & & & & & -0.02 \\
\hline & & & & & & $(0.02)$ \\
\hline \multirow[t]{2}{*}{ Routine (worker level)* Routine (occup. level) } & & & & & & 0.02 \\
\hline & & & & & & $(0.02)$ \\
\hline Non-Routine Manual (worker level) & & & & & & $0.04 *$ \\
\hline * Non-r. Manual (occup. level) & & & & & & $(0.02)$ \\
\hline Worker-/workplace controls & No & Yes & Yes & Yes & Yes & Yes \\
\hline 39 occupation dummies & No & No & Yes & No & No & - \\
\hline \multirow[t]{2}{*}{ Constant } & $2.73 * * *$ & $2.63 * * *$ & $2.65 * * *$ & $2.62 * * *$ & $2.63 * * *$ & $2.58 * * *$ \\
\hline & $(0.03)$ & $(0.03)$ & $(0.05)$ & $(0.05)$ & $(0.05)$ & $(0.04)$ \\
\hline F(Task variables) & $30.78 * * *$ & $26.50 * * *$ & $8.56 * * *$ & & $8.01 * * *$ & $11.86 * *$ \\
\hline F(Occ-lev. Task var) & & & & $70.09 * * *$ & $33.17 * * *$ & $15.87^{* *}$ \\
\hline R-squared & 0.19 & 0.37 & 0.45 & 0.41 & 0.42 & - \\
\hline $\mathrm{N}$ & 1525 & 1525 & 1525 & 1525 & 1525 & 1365 \\
\hline
\end{tabular}

Notes: Worker controls are education, gender, experience, experience squared, immigrant background. Workplace controls are supervisory status, firm size, new manufacturing/process technologies, new computer programs, increases in skill requirements, economic sector, firm location (West/East-Germany). M6 add. includes social background, \%share of VET/univ. graduates in the occupation. Robust standard errors in parentheses; $+p<0.10, * p<0.05, * * p<0.01, * * * p<0.001$. 